\title{
A AUTONOMIA DO CUIDADO EXERCIDO POR ADOLESCENTES PARA UM VIVER SAUDÁVEL: O OLHAR DA ENFERMAGEM
}

\author{
Jacira Nunes Carvalho', Alacoque Lorenzini Erdmann², Mary Elizabeth de Santana ${ }^{3}$
}

\begin{abstract}
RESUMO: Estudo descritivo e qualitativo, teve por objetivo compreender o significado da autonomia do adolescente para o cuidado de si e suas interações na perspectiva de um viver saudável. Utilizou-se o referencial teórico metodológico da complexidade e a Grounded Theory. Os dados foram coletados por meio de entrevistas, textos, recorte e colagem, entre fevereiro a novembro de 2009. Foram participantes 27 pessoas, entre adolescentes, pais, professores e enfermeiros de uma unidade de saúde e uma escola de Belém, Estado do Pará. Os resultados apontaram para o modelo "entendendo a relação entre autonomia e dependência do adolescente para o cuidado de si na perspectiva do viver saudável" ancorado em seis categorias que se interrelacionam na sua explicação. Compreendeu-se que, na administração do processo construtivo da autonomia, o adolescente vivencia a ação/retroação nos diversificados contextos e percebe a sua dependência diante das diferentes relações desafiadoras frente à realidade do viver uma existência saudável.
\end{abstract}

PALAVRAS-CHAVE: Autonomia pessoal; Adolescente; Dependência; Enfermagem.

\section{THE AUTONOMY OF CARE EXERCISED BY ADOLESCENTS FOR A HEALTHY LIFE: THE VIEW OF NURSING}

\begin{abstract}
This descriptive and qualitative study had as its objective to understand the meaning of the adolescent's autonomy of self-care and its interactions in the perspective of a healthy life. Grounded Theory and the theoretical, methodological approach of complexity were utilized. The data were collected via interviews, texts and newspaper clippings between February and November 2009. There were 27 participants, including adolescents, parents and teachers and nurses from a health unit and a school in Belém, Pará State. The results pointed to a model termed 'understanding the relationship between autonomy and dependence of the adolescent for self-care in a context of healthy living', anchored in six categories which interrelate in their explanation. It was understood that in the administration of the constructive process of autonomy, the adolescent experiences action/retroaction in differing contexts and is aware of his/her dependence before different challenging relationships in the face of the reality of living a healthy existence. KEYWORDS: Personal autonomy; Adolescent; Dependency; Nursing.

\section{LA AUTONOMÍA DEL CUIDADO EJERCIDO POR ADOLESCENTES PARA UN VIVIR SALUDABLE: LA MIRADA DE LA ENFERMERÍA}

RESUMEN: Estudio descriptivo y cualitativo, tuvo por objetivo comprender el significado de la autonomía del adolescente para el cuidado de sí mismo y sus interacciones en la perspectiva de un vivir saludable. Fue utilizado el referencial teórico metodológi $\neg$ co de la complexidad y la Grounded Theory. Los datos fueron recogidos por medio de entrevistas, textos, recorte y pegamiento, entre febrero y noviembre de 2009. Fueron participantes 27 personas, entre adolescentes, padres, profesores y enfermeros de una unidad de salud y una escuela de Belém, Estado del Pará. Los resultados apuntaron para el modelo "entendiendo la relación entre autonomía y dependencia del adolescente para el cuidado de sí en la perspectiva del vivir saludable" basado en seis categorías que se interrelacionan en su explicación. Se ha comprendido que, en la administración del proceso constructivo de la autonomía, el adolescente vive la acción/retroacción en los distintos contextos y percibe su dependencia delante de las diferentes relaciones desafiadoras a la realidad del vivir una existencia saludable. PALABRAS CLAVE: Autonomía personal; Adolescente; Dependencia; Enfermería.

\footnotetext{
${ }^{1}$ Enfermeira. Doutora em Filosofia da Enfermagem. Professora da Faculdade de Enfermagem da Universidade Federal do Pará. Líder do Grupo de Estudo de Políticas em Saúde no Cuidado de Enfermagem Amazônico - EPOTENA.

${ }^{2}$ Enfermeira. Doutora em Filosofia da Enfermagem. Professora do Departamento e do Programa de Pós-Graduação em Enfermagem da Universidade Federal de Santa Catarina. Coordenadora do Grupo de Estudos e Pesquisas em Administração, Gerência do Cuidado e Gestão Educacional em Enfermagem e Saúde - GEPADES. Pesquisadora responsável por este trabalho.

${ }^{3}$ Enfermeira. Doutora em Enfermagem. Professora da Faculdade de Enfermagem da Universidade Federal do Pará. Membro do EPOTENA. Co-orientadora deste trabalho.
}

\author{
Autor correspondente: \\ Jacira Nunes Carvalho \\ Universidade Federal do Pará \\ Passagem Álvaro Adolfo, 64 - 66085-030 - Belém-PA-Brasil \\ E-mail: jacira@ufpa.br
}

Recebido: $25 / 05 / 10$

Aprovado: 28/02/11

Cogitare Enferm. 2011 Abr/Jun; 16(2):268-74 


\section{INTRODUÇÃO}

A adolescência pode ser entendida como um período de vida constituído por algumas fases. Ela é uma invenção do século XX, impregnada por uma série de ritos, diferenciando-se de acordo com cada cultura $^{(1)}$; compreende uma população estimada em alguns milhões que vem despertando a atenção e a preocupação pela alta vulnerabilidade à diferentes tipos de agravos.

O desenvolvimento do adolescente ocorre em ciclos de evolução global, caracterizados por profundas transformações, com o indivíduo quase sempre mergulhado em um labirinto de dúvidas e inúmeras interrogações ${ }^{(1)}$.

Situações críticas são evidenciadas em relatórios diversos $^{(2-4)}$ e podem ser consideradas frutos das buscas por satisfações e prazeres, de uma mente ainda inexperiente, mas ávida por novas descobertas e de um corpo em mutação, ainda desconhecido. Nesta corrida, o adolescente se esforça para adquirir sua autonomia, que significa ter domínio para dirigir a própria vida, para definir metas, definir sentimentos de competência e habilidade para regular as próprias ações ${ }^{(5)}$.

Temos como premissa que autonomia humana significa buscar a compreensão profunda da sua liberdade, sempre mediada pelas múltiplas experiências históricas do viver ${ }^{(6)}$. Diante de tal premissa, a autonomia é construída na medida em que existe uma relação do mundo interno do adolescente e de sua própria autoorganização com as condições externas em que ele se desenvolve. Sendo assim, para conhecer o potencial de autonomia do sujeito, é fundamental compreender que tipo de relações o adolescente estabelece na sua vida $\operatorname{social}^{(7)}$.

O desenvolvimento da autonomia é parte do processo de formação do jovem e envolve, necessariamente, transformações nas relações familiares, com o intuito de prepará-lo para o ingresso na vida adulta. Transformações estas que nem sempre os pais estão dispostos a realizar; as mudanças estão relacionadas a autoridade, disciplina, estilo de vida, educação e comunicação e, principalmente, de adaptação ${ }^{(8)}$.

Nessa conjuntura, situa-se a família como tendo papel importante no desenvolvimento do cuidado à saúde de seus membros, visto que em algumas situações os serviços assistenciais não têm atendido de forma satisfatória as necessidades dessa população ${ }^{(9)}$. Por isso, torna-se necessária a elaboração de estratégias que visem a orientação e priorizem a família como centro do processo de cuidado à saúde do adolescente.
Diante dessa possibilidade, foi objetivo desse estudo compreender o significado de autonomia do adolescente para o cuidado de si e suas interações na perspectiva de um viver saudável.

\section{METODOLOGIA}

É um estudo qualitativo-exploratório, realizado pelo método da Teoria Fundamentada nos Dados (TFD), ou Grounded Theory ${ }^{(10)}$, e sustentado na teoria da complexidade.

O estudo foi desenvolvido em Belém, Estado do Pará. Os participantes foram oriundos da Unidade de Saúde Canal da Visconde, que trabalha na Estratégia de Saúde da Família, e professores da Escola Estadual de Ensino Fundamental e Médio Rodrigues Pinagés. $\mathrm{O}$ número de participantes e os respectivos grupos amostrais foram se configurando a partir da análise dos dados e das reflexões sobre as categorias que iam sendo construídas. Os grupos e participantes foram incluídos para garantir refinamento e densidade às categorias iniciais, utilizando-se a técnica de Amostragem Teórica, tal como definido pela TFD. Esta consiste em basear-se nos conceitos e hipóteses conceituais emergentes durante o processo de análise.

Os sujeitos desta pesquisa foram 17 adolescentes, para os quais utilizamos nomes de rios do Estado do Amazonas; quatro pais, identificados por peixes da região; dois professores, identificados por aves; e quatro enfermeiros, identificados por madeiras tropicais.

Seguindo os critérios éticos definidos na Resolução 196/96 do Conselho Nacional de Saúde ${ }^{(11)}$; a pesquisa teve parecer favorável do Comitê de Ética da Universidade Federal de Santa Catarina - UFSC sob n. 279/08 e autorização da Secretaria Municipal de Saúde de Belém

A coleta dos dados foi realizada por meio de textos escritos pelos adolescentes de 12 a 14 anos; de recorte e colagem em grupo de adolescentes de 15 a 16 anos; e de entrevistas com os adolescentes de 17 a 18 anos e demais participantes e registradas em gravador digital. A coleta de dados foi realizada nos meses de fevereiro a novembro de 2009.

Com os adolescentes, a coleta ocorreu em três momentos distintos e em três grupos. No intuito de averiguar os conceitos elaborados, dirigimo-nos para o segundo grupo amostral, os pais. As falas e significados destes apontaram, por sua vez, para a existência de outros parceiros potenciais nesta construção. Assim, partimos para o terceiro grupo amostral, os professores e enfermeiros 
A análise foi realizada de acordo com os pressupostos estabelecidos pela TFD, ou seja, os dados foram coletados, codificados e analisados simultaneamente e de forma comparativa.

\section{RESULTADOS}

A análise dos dados permitiu a identificação da categoria conceitual "entendendo a relação entre autonomia e dependência do adolescente para o cuidado de si na perspectiva do viver saudável". Esta categoria retrata a compreensão dos significados de autonomia para o cuidado e viver saudável evidenciada pelos adolescentes, família e profissionais da educação e saúde.

Esta categoria foi representada por meio de conceitos organizados e expressa nas subcategorias que a compõem e organizadas numa ordem estratégica para ordenamento a um processo que ocorre num sistema de circularidade e recursividade que explica o fenômeno encontrado.

O fenômeno por nós identificado no transcurso desta pesquisa foi a experiência do adolescente para entender a relação que há entre a sua autonomia e a dependência para cuidar-se na perspectiva de um viver saudável. Este fenômeno se explica pelas categorias que seguem.

$O$ adolescente expressando a necessidade de ajuda na construção da autonomia para o cuidado de si foi a categoria que emergiu como condição causal neste processo, por indicar necessidades de aconchego, proteção e a existência de uma família presente que o conduza no exercício de sua autonomia para um viver saudável. Esta necessidade pode ser percebida nas falas a seguir:

Bem, a minha mãe está sempre ali, me orientando para o cuidado higienico e cuidado com minhas roupas intimas. (Japurá)

Logo a minha mãe me levou ao oftalmologista. Sei que posso sempre contar com ela. (Coary)

$O$ adolescente expressando a necessidade de ajuda na construção da autonomia para o cuidado de si mostra que é sensível aos sentimentos de afeto e à vinculação com os membros de sua família. Neste espaço, combina a estima com exigências de aprendizagens diante do seu desenvolvimento. A adolescência é considerada uma fase na qual as transformações orgâ- nicas implicam demasiadamente em redes de relações, quer sejam elas a família, a escola, a sociedade e todas as demais em que sejam possíveis o relacionamento humano, conforme se verifica nos relatos:

Alguns adolescentes, se não a maioria, necessitam de orientações da família e até de amigos para melhorar suas ações de cuidado. (Xingú)

A gente precisa de pessoas que possam ouvir pessoas, que estejam dispostas a entender o que a gente precisa. A boa relação com a família é muito importante. (Purus)

Reconhecendo o ambiente social como espaço de influências para o adolescente desenvolver a autonomia do cuidado de si para um viver saudável foi referida como a categoria que representa o contexto nesse processo. Entendemos que ela deve ser tratada como um sistema complexo, em virtude de suas múltiplas relações com o desenvolvimento do ser. A família é sempre a entrada para este sistema, pois é a partir dela que o adolescente se encaminha para outras estruturas e ambientes sociais durante seu processo de viver, situação observada na fala a seguir:

O fato de morar neste espaço do Canal não tem influenciado elas, pois isso vai depender de cada adolescente aqui desse pedaço. Eu sempre digo a elas: "olhem com quem andam". Não é que não se deva cumprimentar. Agora, a gente não pode é sair de casa e se meter com eles. (Pintado)

Consideramos a categoria Relacionando os aspectos políticos e sociais da atenção à saúde do adolescente como condição interveniente e entendemos que a ausência da família, em função das necessidades sociais de trabalho, muitas vezes torna-se motivo para o crescente número de doenças depressivas, obesidade, assim como de comportamentos desviantes do adolescente. Neste aspecto, acreditamos que as instituições públicas, principalmente escolares, poderiam minimizar este problema, mantendo a criança e o adolescente em dois turnos na escola, realizando a aproximação com a família. Dessa forma, pais, alunos e professores teriam oportunidades de discutir e trabalhar as situações de violência que hoje amedrontam a sociedade. Exemplos podem ser percebidos nas falas que seguem:

A gente tem medo da violência contra os filhos, porque 
onde você está, principalmente os jovens desavisados, já tem um querendo lhe fazer a cabeça [...]. No caso do meu filho, ele não está preparado, pode ser influenciado. (Pirarucu)

A escola virou um campo de brigas entre alunos. A gente está observando que ultimamente não tem quase diferença entre violência na escola e a violência fora da escola. (Arara)

Algumas escolas se tornaram um campo muito pequeno para que adolescentes, no auge de sonhos e devaneios, possam alçar os seus voos. Diante do que oferece a internet, alguns professores não acompanharam o avanço tecnológico. A sala de aula se tornou uma prisão que embota pensamentos, e as ideias são aprisionadas na mesmice de cada dia de aulas desinteressantes.

Como resultado, crianças e adolescentes abandonam a escola e embrenham-se em mundos diversificados, das gangues, das drogas, da prostituição e tantos outros tipos de envolvimentos. O Programa de Saúde do Adolescente - PROSAD, instituído em 1989, que seria também um programa de ajuda, sendo uma iniciativa pública, não conseguiu, até o momento, desprender-se das estruturas organizacionais legislativas para assumir-se como uma prática no cotidiano de cada Unidade de Saúde. As poucas iniciativas se deparam com estruturas insuficientes, falta de planejamento e pessoal não capacitado para atender uma clientela tão específica e com características complexas.

Para cuidar de todos os filhos, eu sempre procuro o Centro de Saúde, mesmo com as dificuldades que se tem para conseguir uma consulta. Tratamento diferente às vezes é só o das freiras, elas passaram uns remédios para meu filho, depois de muita correria teve que internar. (Pintado)

[...] somente quando existir uma politica de saúde e educação realmente comprometida em educar $e$ oferecer serviços de qualidade nos órgãos públicos, qualificar profissionais na educação e saúde, desde a assistência ao pré-natal, levando esta mãe a desenvolver sua identidade e autoestima e repassar isso para os seus filhos. (Andirobeira)

A adolescência é uma fase de sonhos. Não podemos permitir que os jovens despertem para uma realidade assustadora, onde os homens deixaram de se amar, onde ronda a violência e a solidariedade não se faz presente, onde a escola não é mais um lugar de paz e tranquilidade, um lugar onde alguém possa se sentir protegido.

Na condição de estratégias utilizadas no processo de compreensão do fenômeno em ação, duas categorias emergiram, a saber:

\section{Indicando a escola como parceira na aquisição da autonomia para o cuidado de si por adolescentes para um viver saudável.}

Para iniciar esta análise, utilizamos fragmentos da fala de um participante:

[...] que professor está ministrando essa disciplina? Qual o perfil desse professor? Qual a concepção que ele tem de família? [...] O modo como vai ser repassado é que entra o professor [...]. O modo como pode ser transmitido é que pode ser poesia, questão ambiental, história das sociedades, trabalhando consciência, arte, cinema e outras culturas. [...]. Estes alunos terão contatos com outras possibilidades, terão outras visões e outras perspectivas diferentes de suas realidades [...]. A mudança de cenário pode ser propícia às mudanças nas percepções das diferentes realidades. (Araponga)

Olhamos a escola como um dos espaços socioculturais fundamentais para a humanização das gerações mais jovens. Entretanto, vê-se nela uma realidade preocupante, onde algumas crianças e os adolescentes não têm respeito aos seus professores e alguns destes perderam a sua segurança e sua postura. $O$ professor deixou de ser o ídolo, o pilar, o sustentáculo da escola. O professor mudou de nome, hoje é instrutor, facilitador, coordenador; deixou de ser idealista, criativo, alegre. No entanto, ainda reconhecemos a escola como um dos espaços privilegiados para a formação do adolescente. Todavia, ela não atende às expectativas das demandas sociais. Não consegue ser criativa e não desperta, nem mesmo na família, o sentimento de parceria.

Com possibilidade de somar conhecimentos, experiências e trabalho, outra categoria emergiu como estratégia a ser utilizada para auxiliar no desenvolvimento do adolescente e na execução de cuidados de si que venham propiciar saúde na perspectiva de um viver saudável:

Valorizando a orientação do profissional de saúde no processo de aquisição da autonomia do adolescente 
para o cuidado de si com vistas a um viver saudável.

Para corresponder a essa necessidade, é essencial que os profissionais de saúde demonstrem não somente o aprimoramento técnico científico, mas que tenham atitude humana e sensibilidade ao trabalhar com adolescentes. Por sua vez, as ações direcionadas aos adolescentes necessitam estratégias eficazes e eficientes, levando em consideração a suscetibilidade e vulnerabilidade a que estão submetidos:

[...] somente quando você está trabalhando em uma unidade de referência para adolescentes, pois no diaa-dia, o que observamos nas Unidades de Saúde, é a execução dos programas de imunização, odontologia [...]. É quando este adolescente já comparece com alguma patologia já instalada. (Andirobeira)

[...] é muito importante este profissional na transição entre criança e a vida do jovem adulto. Ele poderá lhe dar orientações e ser a pessoa que este adolescente confia. (Acapú)

É importante atentar para o fato de que não só os profissionais estejam preparados, mas que se tenha uma estrutura compatível ao desenvolvimento de ações coletivas e individualizadas, proporcionando aos adolescentes, quando necessário, a privacidade para o diálogo com o profissional. Esta estrutura deve ser complementada com equipamentos e material necessário ao atendimento resolutivo do adolescente:

[...] o profissional enfermeiro precisa estar preparado para trabalhar junto ao adolescente, e o serviço melhor estruturado. (Seringueira)

Ao fazer essas considerações, vemos que a Enfermagem vem progredindo expressivamente, buscando firmar-se como detentora do saber científico sem, no entanto, deixar de lado o aspecto humanitário da profissão.

Compreendendo a dependência como dimensão necessária à aquisição da autonomia do cuidado de si pelo adolescente para um viver saudável é a categoria considerada consequência nesse processo vivenciado pelos adolescentes deste estudo. Tomar consciência dessa dimensão poderá ser um fator que contribuirá para o estabelecimento de estratégias facilitadoras no processo de cuidar/assistir/orientar esta clientela.
A compreensão da dimensão nos faz refletir sobre a dependência humana e sobre a necessidade de se desenvolver sensibilidades para as diferentes situações esperadas no processo de desenvolvimento humano.

\section{DISCUSSÃO}

O fenômeno da adolescência, explicado à luz do pensamento complexo, pode ser compreendido pelo princípio das múltiplas dependências que vão se somando ao processo de sermos independentes, extraído dos princípios fundamentais que governam a relação entre a auto-organização dos seres vivos e o ecossistema/organização onde estes se inserem.

\begin{abstract}
A independência cresce ao mesmo tempo em que a dependência. Quanto mais autônomo, quanto mais complexo se torna um ser, mais esta complexidade depende das complexidades eco-organizadoras que o alimentam. A liberdade depende de suas condições de formação e desenvolvimento e, uma vez consumada, permanece como liberdade retroagindo sobre as condições das quais depende ${ }^{(12: 83)}$.
\end{abstract}

O adolescente, em sua essência humana complexa, tem necessidade de vivenciar acontecimentos perturbadores e agressivos que desempenham um papel de desafio e que desencadeiam realizações e superações. Entretanto, esses mesmos seres que requerem perturbações para sua realização têm em contrapartida uma necessidade de afetividade, cuidado, atenção, carícia, abraço maternal, fraternidade e proteção dos adultos.

Assim, é de suma importância reconhecer que adolescentes e todos os demais componentes do ambiente natural e social são interdependentes e estão interconectados nesta rede ${ }^{(13)}$.

\begin{abstract}
Tais seres só podem construir e manter sua existência, sua autonomia, sua individualidade e sua originalidade na relação ecológica, ou seja, na e pela dependência com relação a seu ambiente; daí a idéia alpha de todo pensamento ecologizado: a independência de um ser vivo requer sua dependência com relação a seu ambiente. Todo ser aberto age e retroage em seu ambiente ${ }^{(14: 25)}$
\end{abstract}

Sabe-se que a família exerce importante papel na construção do conhecimento em relação à sexualidade do adolescente. Porém, muitos pais encontram algumas dificuldades em assumir esse papel e acabam por responsabilizar a escola por esta função ${ }^{(7)}$. Contudo, o trabalho realizado pela escola é complementar e não substitui a função da família.

Análises recentes têm indicado que não vêm sendo 
cumpridas as funções atribuídas à escola, conforme a expectativa social ${ }^{(15)}$. Entretanto, todas essas evidências precisam ser analisadas em sua complexidade e focadas à luz das políticas públicas, especialmente das educacionais, das crenças e das metas que no cotidiano regulam as práticas de ensino e de aprendizagem, especialmente das relacionadas à formação dos profissionais da educação ${ }^{(15)}$. Precisamos acreditar que a escola pode mudar e corresponder às necessidades de milhões de jovens brasileiros.

Nessa expectativa, consideramos que, com o estreitamento das relações entre os professores e familiares, estes podem ter maiores informações a respeito de quem são os alunos, suas famílias, sua cultura, sua vida cotidiana, e isso pode ajudá-los a desenvolver o trabalho de forma mais competente. A relação entre escola e famílias, dada a sua complexidade, deve ser tratada no âmbito de cada realidade.

Para os adolescentes todos os assuntos referentes à sexualidade devem ser abordados na escola, e eles indicam as DST/Aids como um assunto de especial atenção ${ }^{(16)}$. Tem se deixado de discutir a dimensão subjetiva da sexualidade, tornando o conhecimento adquirido distante da realidade vivenciada pelo aluno. Só com a mudança desse cenário o adolescente tem condições de tomar consciência da realidade e sofrer/ promover a transformação tão almejada.

Dessa forma, para garantir a efetividade das intervenções, as ações deverão estar pautadas no método participativo, como meio de encontrar subsídios para análise, compreensão e interpretação de achados qualificados para o estabelecimento do diagnóstico das necessidades e do perfil do grupo com que se trabalha ${ }^{(17)}$.

Toda criança ou adolescente tem direito a ser criado e educado no seio da sua família e, excepcionalmente, em família substituta, assegurada a convivência familiar e comunitária $[\ldots]^{(18: 13)}$.

De acordo com o Estatuto da Criança e do Adolescente - ECA, todas as medidas de proteção reforçam o vínculo familiar como primeiro e fundamental no desenvolvimento da criança e do adolescente.

Como a família é a primeira instituição socializadora da criança, é ela que desempenha o papel de organizadora primária da sociabilidade, bem como dos laços de dependência emocional entre seus membros. As relações emocionais assumem aspectos diversos na dependência da situação social e econômica na qual a família se insere. Em sua dinâmica, portanto, a família sofre influência direta do econômico e do cultural.

Assim, dependemos da escola, dos serviços públicos ou privados de qualquer natureza, direta ou indiretamente. Portanto, a dependência é palavra/situação presente durante o processo de amadurecimento do ser humano e permanece por toda sua vida. Não existe possibilidade de qualquer ser humano viver e desenvolver-se prescindindo da dependência. Somos seres dependentes, vivemos da dependência, a nossa autonomia é alimentada pela dependência ${ }^{(19)}$.

\section{CONSIDERAÇÕES FINAIS}

Nessa trajetória para compreender o significado de autonomia adolescente para o cuidado de si e suas interações na perspectiva de um viver saudável, foi possível abstrair o fenômeno entendendo a relação entre autonomia e dependência do adolescente para o cuidado de si na perspectiva do viver saudável. Após a análise à luz da complexidade e conduzindo a interpretação segundo a teoria fundamentada nos dados, percebemos os participantes deste estudo como sujeitos histórico-sociais, com diferentes expectativas e sentimentos sobre a adolescência.

Ao assumir a dependência da família para desenvolver a autonomia do cuidado, o adolescente sinaliza que a família mostra-se a única possibilidade da sociedade para se desenvolver de forma digna, exercendo seu papel agregador, fortalecendo seus vínculos e concretizando sua participação no desenvolvimento de seus filhos.

Essas famílias necessitam de uma estrutura social que as orientem nessa etapa, que para elas é também repleta de ajustes e incertezas, de maneira que possam entrar em sintonia com os filhos adolescentes e conviver de forma harmoniosa.

Há queixas da escola, porém, os participantes sentem que este espaço é imprescindível para o desenvolvimento social e intelectual do sujeito adolescente, uma vez que nela encontram-se as pessoas de sua idade, com os mesmos interesses e onde se formam os grupos de pertença. Esses grupos são importantes para desenvolver nos adolescentes lideranças, respeito, valores, ética e convivência social.

Os adolescentes valorizam o cuidado à saúde e vislumbram a existência de serviços que correspondam as suas necessidades e de profissionais capacitados para o seu atendimento.

Entendemos que a relevância deste estudo passa 
pela possibilidade de mudanças radicais de comportamentos e atitudes e até mesmo de paradigmas em relação à implementação de programas sociais mais consequentes. Não é mais possível falar em políticas públicas eficazes sem destacar a família como potencializadora destas ações.

Diante do conhecimento gerado por este estudo, espera-se, dentro dos limites a que este se propôs, ter contribuído para que este tema venha despertar o interesse de muitas outras pessoas, que seja debatido, repensado e olhado por várias vertentes. As ideias apresentadas são apenas uma introdução, um convite à discussão bem mais ampla que envolva toda a sociedade numa corrente cujos elos venham agregar cada vez mais o adolescente a um mundo melhor.

\section{REFERÊNCIAS}

1. Pigozzi V. Celebre a autonomia do adolescente: entendendo o processo de iniciação na vida adulta. São Paulo: Gente; 2002.

2. Fundo das Nações Unidas para a Infância (BR). Relatório da situação mundial da infância. Caderno Brasil. [Internet]. Brasília: UNICEF; 2008. 64p. [acesso em 15 mai 2009]. Disponível: http://www.unicef.org/lac/ cadernobrasil2008.pdf

3. Associação Nacional dos Centros de Defesa da Criança e do Adolescente (BR). Relatório sobre a situação dos direitos da criança e do adolescente no Brasil. Brasília: ANCED; 2004.

4. Ministério da Saúde (BR). Brasil acelera redução de gravidez na adolescência. [Internet]. Notícias. Portal da Saúde, 2010. [acesso em 25 jun 2010]. Disponível: http://migre.me/51Lxz

5. Silva JMS. Sujeitabilidade e autonomia: um olhar hermenêutico da formação de lideranças no mundo plural. Interfaces. 2006;6(2):1-15.

6. Morin EPI. A sociedade em busca de valores. Lisboa: Instituto Piaget; 1996.

7. Ríos González JA. Los ciclos vitales de la família y la pareja. ¿Crisis u oportunidades; Madrid: Editorial CCS; 2005.

8. Marcon SS, Lopes MCL, Fernandes J, Antunes CRM, Waidman MAP. Famílias cuidadoras de pessoas com dependência: um estudo bibliográfico. Online Braz J
Nurs. [Internet]. 2006;5(1) [acesso em 20 jan 2006]. Disponível: http://migre.me/51Lzc

9. Elsen I. Cuidado familial: uma proposta inicial de sistematização conceitual. In: Elsen I, Marcon SS, Silva MRS, organizadores. O viver em família e sua interface com a saúde e a doença. 2ª ed. Maringá: Eduen; 2004.

10. Strauss A, Corbin J. Pesquisa qualitativa: técnicas e procedimentos para o desenvolvimento de teoria fundamentada. $2^{\mathrm{a}}$ ed. Porto Alegre: Artmed; 2008.

11. Ministério da Saúde (BR). Conselho Nacional de Saúde. Diretrizes e normas regulamentadoras de pesquisa envolvendo seres humanos. Resolução n. 196 de 10 de outubro de 1996. Brasília; 1996.

12. Morin E. O método 6: ética. São Paulo: Sulina; 2005.

13. Bronfenbrenner U. A ecologia do desenvolvimento humano: experimentos naturais e planejados. Porto Alegre: Artes Médicas; 1996.

14. Morin E. O método 1: a natureza da natureza. Porto Alegre: Sulina; 2008.

15. Reali AMMR, Tancredi RMSP. Desenvolvendo uma metodologia de aproximação entre a escola e as famílias dos alunos com a parceria da universidade. In: Seminário de Metodologia para Projetos de Extensão, 4, 2001, São Carlos. [anais eletrônicos] Rio de Janeiro, 2001 [acesso em 23 mai 2009]. Disponível: http://www. itoi.ufrj.br/sempe/index.htm

16. Madureira L, Marques IR, Jardim DP. Contracepção na adolescência: conhecimento e uso. Cogitare Enferm. 2010;15(1):100-5.

17. Gomes VLO, Telles KS, Roballo EC. Grupo focal e discurso do sujeito coletivo: produção de conhecimento em saúde de adolescentes. Esc Anna Nery. 2009;13(4): 856-62.

18. Brasil. Lei n. 8069 de 13 de julho de 1990. Dispõe sobre o Estatuto da Criança e do Adolescente e dá outras providências. [Internet]. Brasília, 1990. [acesso em 5 ago 2008]. Disponível: http://www.planalto.gov.br/ccivil/ LEIS/L8069.htm

19. Morin E. O método 3: o conhecimento do conhecimento. Porto Alegre: Sulina; 1999. 